\title{
A Neutron Diffraction Investigation of High Valent Doped Barium Ferrite With Super-wide Tunable Microwave Absorption
}

\section{J. Li ( $\sim$ lijuna@hit.edu.cn )}

Harbin Institute of Technology https://orcid.org/0000-0002-7645-1997

\section{Yang Hong}

Harbin Institute of Technology

\section{San $\mathrm{He}$}

Harbin Institute of Technology

Weike Li

Harbin Institute of Technology

\section{Han Bai}

Harbin Institute of Technology

\section{Yuanhua Xia}

China Academy of Engineering Physics Institute of Nuclear Physics and Chemistry

\section{Guangai Sun}

China Academy of Engineering Physics Institute of Nuclear Physics and Chemistry

\section{Zhongxiang Zhou}

Harbin Institute of Technology

\section{Research Article}

Keywords: barium ferrite, neutron diffraction, microwave absorption

Posted Date: February 9th, 2021

DOI: https://doi.org/10.21203/rs.3.rs-199355/v1

License: (1) (1) This work is licensed under a Creative Commons Attribution 4.0 International License. Read Full License 


\title{
A neutron diffraction investigation of high valent doped barium
}

\section{ferrite with super-wide tunable microwave absorption}

\author{
Jun $\mathrm{LI}^{a, b, \uparrow^{*},}$, Yang $\mathrm{HONG}^{c, \dagger}$, San $\mathrm{HE}^{a, b}$, Weike $\mathrm{LI}^{a, b}$, Han $\mathrm{BAI}^{a, b}$, Yuanhua XIA ${ }^{d}$
}

Guangai $\mathrm{SUN}^{d}$ and Zhongxiang $\mathrm{ZHOU}^{a, b, *}$

${ }^{a}$ School of Physics, Harbin Institute of Technology, Harbin 150001, China

${ }^{b}$ Heilongjiang Provincial Key Laboratory of Plasma Physics and Application Technology, Harbin Institute of Technology, Harbin 150001, China

${ }^{c}$ School of Chemistry and Chemical Engineering, Harbin Institute of Technology, Harbin 150001, China

${ }^{d}$ Key Laboratory for Neutron Physics of CAEP, Institute of Nuclear Physics and Chemistry, Mianyang 621999, China

$\dagger$ Jun Li and Yang Hong contributed equally to this work.

${ }^{*}$ Corresponding author.

E-mail: lijuna@hit.edu.cn, zhouzx@hit.edu.cn

\section{Abstract}

The Barium ferrite $\mathrm{BaTi}_{x} \mathrm{Fe}_{12-x} \mathrm{O}_{19}(x=0.2,0.4,0.6,0.8)$ ceramics doped by $\mathrm{Ti}^{4+}$ (BFTO-x) were synthesized by a modified sol-gel method. The crystal structure and magnetic structure of the samples were determined by neutron diffraction, and confirm that the BFTO- $x$ ceramics were high quality single phase with sheet micro-structure. With $x$ increasing from 0.2 to 0.8 , the $M_{\mathrm{s}}$ decreases gradually but the change of $H_{\mathrm{c}}$ is complex under the synergy of the changed grain size and the magnetic crystal anisotropy field. Relying on the high valence of $\mathrm{Ti}^{4+}$, double resonance peaks are obtained in the curves of $\mu^{\prime \prime}$ and the resonance peaks could move towards the low frequency with the increase of $x$, which facilitate the samples perform an excellent wide-band modulation microwave absorption property. In the $x=0.2$ sample, the 
maximum reflection loss can reach $-44.9 \mathrm{~dB}$ at the thickness of only $1.8 \mathrm{~mm}$, and the bandwidth could reach to $5.28 \mathrm{GHz}$ at $2 \mathrm{~mm}$ when the RL is less than $-10 \mathrm{~dB}$. All the BFTO- $x$ ceramics show excellent frequency modulation ability varying from $18 \mathrm{GHz}$ $(x=0.8)$ to $4 \mathrm{GHz}(x=0.4)$, which covers $81 \%$ of the investigated frequency in microwave absorption field.

Keywords: barium ferrite; neutron diffraction; microwave absorption.

\section{Introduction}

The rapid development of electronic information technology and communication industry has increased the requirements of microwave absorption materials to solve the uncovering electromagnetic interference problems [1]. Thus, developing microwave absorption materials of large reflection loss and broad bandwidth is becoming urgent. The inherent properties of microwave absorbing materials, including complex permeability and permittivity, which are significant in enhancing the reflection loss and broadening the effective bandwidth [2].

The electromagnetic absorbing materials can be classified into a resistive type, a dielectric type, and a magnetic medium type according to the loss mechanism [3-5]. The resistive absorbing materials mainly absorb electromagnetic wave by interaction with an electric field, and the absorption efficiency depends on the conductivity and dielectric constant, include carbon black, metal powder, silicon carbide, graphite, and special carbon fiber [6]. For dielectric absorbing materials, the electromagnetic wave is mainly absorbed by the dielectric polarization relaxation loss, the typical representative is barium titanate ferroelectric ceramics [7]. The attenuation of the electromagnetic 
wave by the magnetic medium type absorbing materials mainly comes from resonance and hysteresis loss, such as ferrite and carbonyl iron [8]. Among all these materials, the ferrite is an ideal microwave absorbing material for the simple preparation process and the stable performance [9].

M-type barium ferrite $\left(\mathrm{BaFe}_{12} \mathrm{O}_{19}\right)$, a versatile material, performs excellent electromagnetic properties due to the large magnetic loss at the natural resonance frequency. Pure barium ferrite has large saturation magnetization, high coercivity, magnetic anisotropy constants and the large magnetic loss at the natural resonance frequency, which make barium ferrite have excellent microwave absorption characteristics. To investigate larger reflection loss, broader bandwidth, and even tunable microwave absorbing material, many kinds of research work on barium ferrite doping modification are carried out. The magnetic loss is related to the content of $\mathrm{Fe}^{3+}$ in barium ferrite, thus the microwave absorption properties can be adjusted when $\mathrm{Fe}^{3+}$ ions are substituted with other trivalent ions or combination of divalent and tetravalent ions. BaM-based cationic substitutions for $\mathrm{Fe}^{3+}$ are used to modify the dielectric and magnetic parameters, which play an important role in reflection loss (RL) calculation. The substitutions for $\mathrm{Fe}^{3+}$ of $\mathrm{BaM}$-based can be divided into two main approaches: covalent cation substitution such as $\mathrm{Ga}^{3+}, \mathrm{In}^{3+}$, and $\mathrm{Er}^{3+}$ and hetervalent cationic combination such as $\mathrm{Co}^{2+}-\mathrm{Ti}^{4+}, \mathrm{Co}^{2+}-\mathrm{Zr}^{4+}, \mathrm{Ni}^{2+}-\mathrm{Ti}^{4+}$, and so on [10-14]. However, recent studies have shown that the introduction of high-valence ions destroys the valence state equilibrium of barium ferrite, resulting in multiple absorption peaks, which can increase the bandwidth of electromagnetic wave absorption of the material 
$[15,16]$.

In this work, we synthesized $\mathrm{BaFe}_{12-x} \mathrm{Ti}_{x} \mathrm{O}_{19}$ (BFTO-x, $\left.x=0.2,0.4,0.6,0.8\right)$ using only tetravalent $\mathrm{Ti}^{4+}$ ions as high valent dopant ions by modified sol-gel method. We systematically analyzed the structure, morphology, magnetic properties and electromagnetic parameters of the sample. By comparing the magnetic structure of the neutron diffraction with the experimental magnetic results, the internal magnetic mechanism of the sample was deeply studied. The modified M-type barium ferrite exhibits better tunability for electromagnetic properties, which have a positive role on the exploration of the novel microwave absorbing materials.

\section{Experimental}

\section{1 Material synthesis}

The $\mathrm{Ti}^{4+}$ doped M-type barium ferrite ceramics $\left(\mathrm{BaFe}_{12-x} \mathrm{Ti}_{x} \mathrm{O}_{19}, x=0.2,0.4,0.6\right.$, 0.8) were prepared utilizing the modified sol-gel method that is more effective than conventional solid state method. Barium nitrate $\left(\mathrm{Ba}\left(\mathrm{NO}_{3}\right)_{2}\right)$, iron nitrate $\left(\mathrm{Fe}\left(\mathrm{No}_{3}\right)_{3} \cdot 9 \mathrm{H}_{2} \mathrm{O}\right)$ and titanium nitrate $\left(\mathrm{Ti}\left(\mathrm{NO}_{3}\right)_{4}\right)$ were weighted in a stoichiometric ratio and dissolved in citric acid solution adequately. The $\mathrm{PH}$ value of the solution was adjusted to 8 by adding ammonia water, then the solution was stirred for $2 \mathrm{~h}$ and aged for $12 \mathrm{~h}$ at room temperature. The mixed solution was placed in $80{ }^{\circ} \mathrm{C}$ water bath for 3 $\mathrm{h}$ to form a sol, which was then transferred to a dry box at $120^{\circ} \mathrm{C}$ for 1 to 2 day until a dry gel was formed. The aerogel was incubated at $210{ }^{\circ} \mathrm{C}$ for $3 \mathrm{~h}$ to remove organic components from the gel. Calcination was carried out at $1200{ }^{\circ} \mathrm{C}$ to get the BFTO- $x$ powder. The powder was pressed into wafers of $13 \mathrm{~mm}$ in diameter, and then the wafers 
were sintered at $1200^{\circ} \mathrm{C}$ for $4 \mathrm{~h}$ in air atmosphere to obtain the BFTO- $x$ ceramics.

\section{2 Characterizations}

The neutron powder diffraction (NPD) experiments were carried out at room temperature using high resolution neutron powder diffractometer (HRND) $(\lambda=1.884 \AA)$ at China Mianyang Research Reactor (CMRR), and the corresponding Rietveld refinement was achieved by FullProf and SARAh. Morphologies were examined using field emission scanning electron microscopy (SEM, ZEISS Merlin Compact). Magnetic properties were investigated using a vibrating sample magnetometer (VSM, Lake Shore 7404). The electromagnetic properties were studied using air-line method, which were mixed with polyvinyl alcohol (PVA) at a mass ratio of $6: 1$. The complex permittivity and permeability were measured from 2 to $18 \mathrm{GHz}$ with a vector network analyzer (Keysight Technologies N5234A).

\section{Results and discussion}

\section{1 Effects of titanium substitution on crystal structure and microstructure}

The neutron diffraction patterns of BFTO- $x(x=0.2,0.4,0.6,0.8)$ ceramics are shown in Figure 1(a), which contains the complete neutron diffraction pattern before and after refinement using Rietveld method. Since the neutron diffraction patterns include both structural and magnetic information, the process of BFTO- $x$ refinement using FullProf can be divided into two parts: structural and magnetic phase [17]. The detailed results of refinement contained structural and magnetic parameters also appear in the Figure 1(a), and the corresponding refinement factors of each components were also shown in the figure. Compared with the neutron diffraction Bragg positions of pure 
barium ferrite, no other impurity peaks were found, indicating that the four components were single phase with space group P63/mmc. Moreover, the corresponding magnetic space group of BFTO- $x$ is $R-3 m: H$, which was determined by utilizing the Sarah Analysis to calculate the possible magnetic space groups [18]. The result of structural refinement shows that the lattice parameters changes little with the increasing of $\mathrm{Ti}$ doping, the corresponding parameters are $x=0.2(a=b=5.8946 \AA, c=23.2225 \AA), x$ $=0.4(a=b=5.8940 \AA, c=23.2354 \AA), x=0.6(a=b=5.8942533 \AA, c=23.2402 \AA)$, and $x=0.8(a=b=5.8944 \AA, c=23.2361 \AA)$. The change may origin from that Ti ion occupies the position of Fe ion in the sublattice, and the atomic radius of $\mathrm{Ti}^{4+} \operatorname{ion}(0.0605$ $\mathrm{nm})$, is basically the same with that of $\mathrm{Fe}^{3+}$ ion $(0.0645 \mathrm{~nm})$. The lattice structure distorted due to the replacement of $\mathrm{Ti}$ ions, leading to the cell parameters have changed concomitantly. Another parameter characterizing the crystal and magnetic structure is the Bragg position. The structure Bragg position does not change with the Ti doping, which is correspond with the refinement result of lattice parameters. However, the magnetic Bragg position changes with the increase of Ti doping. New Bragg position generated when $x=0.6$. This probably because that with the increase of Ti, in order to keep the valence conserve, part of $\mathrm{Fe}^{3+}$ ions converted into $\mathrm{Fe}^{2+}$ ions, generating new Hollande factor. In addition, more analysis about structure are shown in the supporting information Figure S1.

Figure 1(b) shows that the primitive cell of $\mathrm{BaFe}_{12} \mathrm{O}_{19}$ is composed of $10 \mathrm{O}^{2-}$ ions layers, because the radii of $\mathrm{Ba}^{2+}$ ion $(0.142 \mathrm{~nm})$ and $\mathrm{O}^{2-}$ ion $(0.140 \mathrm{~nm})$ are not much different, $\mathrm{Ba}^{2+}$ ion often occupies the position of $\mathrm{O}^{2-}$ ion in the oxygen lattice of the 
crystal. Therefore, certain amounts of barium ions are contained in the close-packed structure of oxygen ions. Meanwhile, $\mathrm{Fe}^{3+}$ ions exist in the interstices of oxygen ions, forming a stable hexahedral structure. $\mathrm{In} \mathrm{BaFe}_{12} \mathrm{O}_{19}, \mathrm{Fe}^{3+}$ ions are distributed over five different positions, named $12 k, 2 a, 2 b, 4 f_{1}$ and $4 f_{2}$ [19]. Magnetic moment orientations of $\mathrm{Fe}^{3+}$ in three positions $(12 k, 2 a, 2 b)$ spin up while those of $4 f_{1}$ and $4 f_{2}$ positions spin down. In order to obtain the information of exact occupation of $\mathrm{Ti}$, the method of neutron diffraction intensity fitting was utilized to explore the occupation probability of Ti as listed in Table 1 . The result of fitting shows that Ti tends to occupy the position $2 \mathrm{a}, 2 \mathrm{~b}$, and $12 \mathrm{k}$, in where Fe is spin-up.

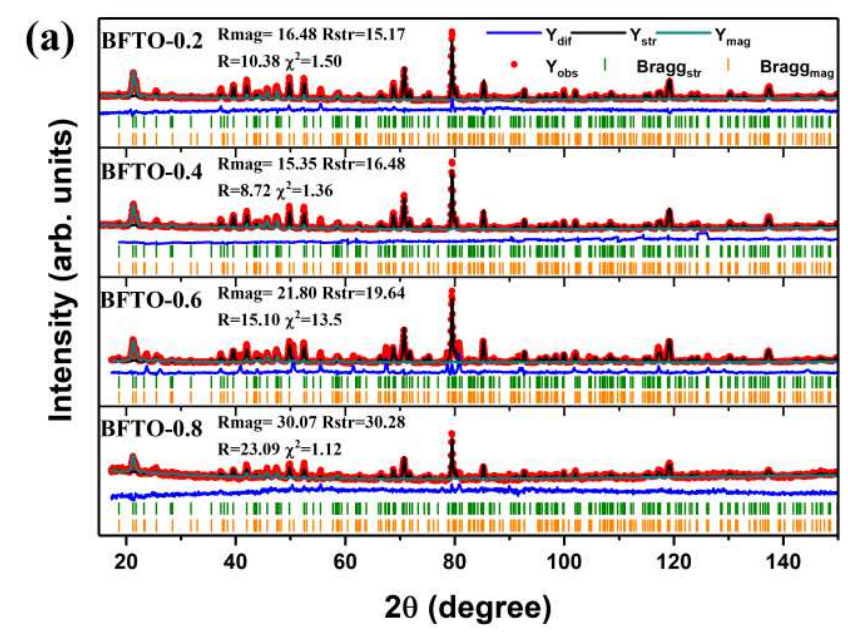

(b)

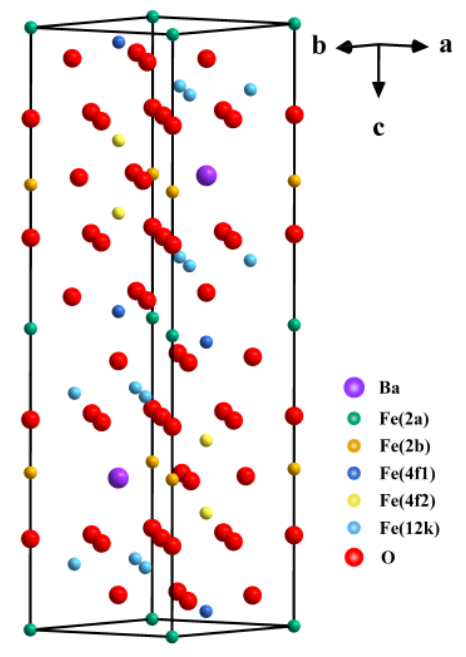

Figure 1. (a) Neutron diffraction and corresponding refinement patterns of BFTO- $x$ ( $x=0.2,0.4$,

0.6, 0.8) ceramics, and (b) the schematic structure of $\mathrm{BaFe}_{12} \mathrm{O}_{19}$.

Table 1. The occupation probability of BFTO- $x$ ceramics.

\begin{tabular}{ccccc}
\hline & $x=0.2$ & $x=0.4$ & $x=0.6$ & $x=0.8$ \\
\hline $2 \mathrm{a}(\mathrm{Fe})$ & 0.08292 & 0.08290 & 0.08083 & 0.07965 \\
$2 \mathrm{a}(\mathrm{Ti})$ & 0.00041 & 0.00043 & 0.00250 & 0.00368 \\
\hline
\end{tabular}




\begin{tabular}{ccccc}
\hline $2 \mathrm{~b}(\mathrm{Fe})$ & 0.07125 & 0.05427 & 0.04083 & 0.02923 \\
$2 \mathrm{~b}(\mathrm{Ti})$ & 0.01208 & 0.02906 & 0.04250 & 0.05410 \\
& & & & \\
$12 \mathrm{k}(\mathrm{Fe})$ & 0.49582 & 0.49830 & 0.49500 & 0.49114 \\
$12 \mathrm{k}(\mathrm{Ti})$ & 0.00417 & 0.00170 & 0.00500 & 0.00860 \\
\hline
\end{tabular}

The surface morphologies of BFTO- $x$ ceramics are shown in Figure 2. It can be observed that all components perform typical hexagonal plates, and the grain boundary is distinct. The particle size of BFTO- $x$ ceramics varies with the increase of $x$, where the grain size of BFTO- 0.4 about $1 \mu \mathrm{m}$ is larger than those of other three components. Compared with the solid state sintering method, the grain size of BFTO ceramics prepared by the sol-gel process is smaller, which has an important effect on coercive force [20].
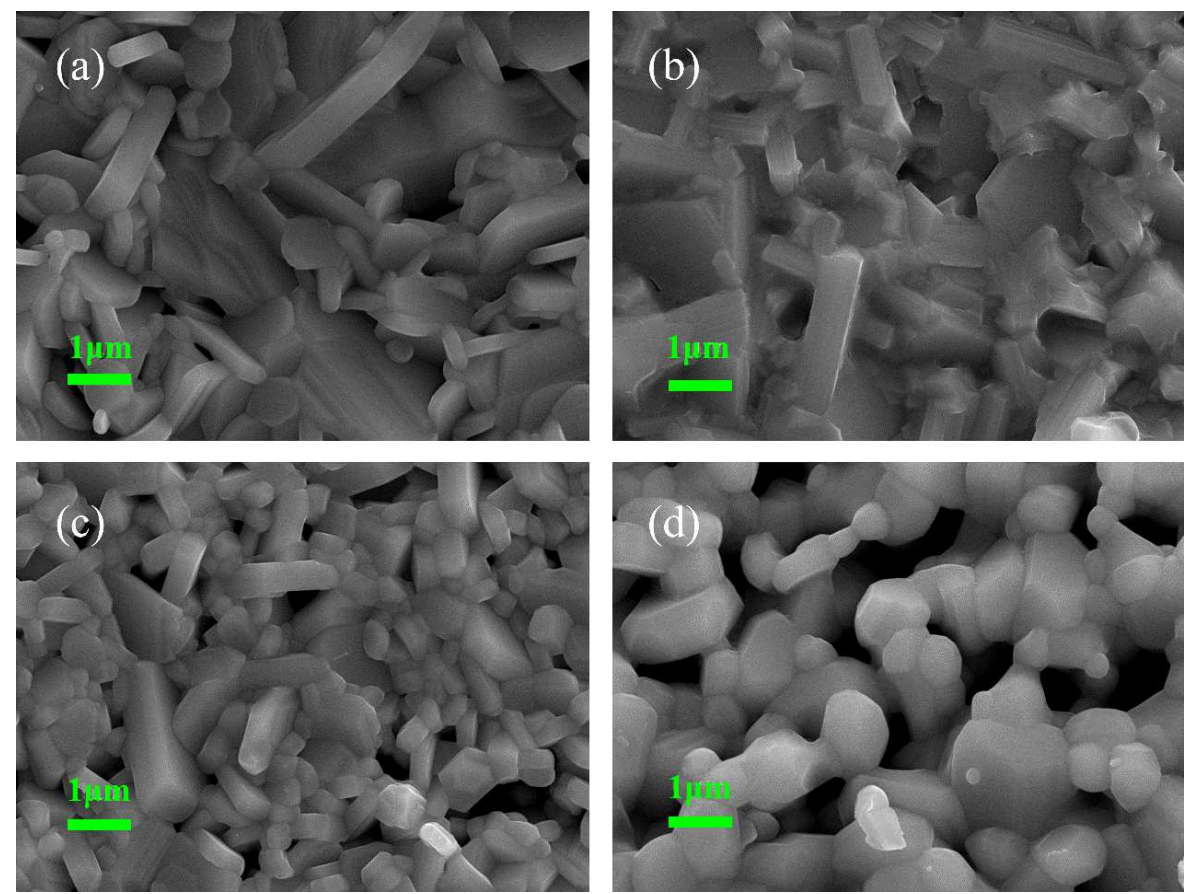

Figure 2. SEM images of BFTO- $x$ ceramics with $x=0.2(\mathrm{a}), x=0.4(\mathrm{~b}), x=0.6(\mathrm{c}), x=0.8(\mathrm{~d})$.

\section{2 Effects of titanium substitution on magnetic properties}

The magnetic properties of BFTO- $x(x=0.2,0.4,0.6,0.8)$ ceramics are derived 
from magnetic hysteresis loops at room temperature in Figure 3. It can be seen that all samples are approaching saturation as the applied field is increased up to $15 \mathrm{kOe}$. With $x$ increasing from 0.2 to 0.8 , the $M_{\mathrm{s}}$ decreases gradually from $31.87 \mathrm{emu} / \mathrm{g}$ to 22.13 emu $/ \mathrm{g}$, while the change trend of $H_{\mathrm{c}}$ is complicated. The change trend of $M_{\mathrm{s}}$ and $H_{\mathrm{c}}$ is related to the magnetic moment of $\mathrm{Fe}^{3+}$ and the occupied position during doping [21].

The replacement from $\mathrm{Ti}^{4+}$ ion to the magnetic $\mathrm{Fe}^{3+}$ ion $\left(5 \mu_{\mathrm{B}}\right)$ would reduce the $M_{\mathrm{S}}$ of barium ferrite ceramics since the $\mathrm{Ti}^{4+}$ ion is non-magnetic, and $M_{\mathrm{s}}$ exhibits a downward trend with the increase of $\mathrm{Ti}^{4+}$ ion doping [22]. It is known that $H_{\mathrm{c}}$ is mainly affected by anisotropic field $\left(H_{\mathrm{a}}\right)$ and grain size. That is, the larger the grain size of ceramics, the smaller the $H_{\mathrm{c}}$. On the other hand, the $H_{\mathrm{c}}$ is proportional to $H_{\mathrm{a}}$. According to the formula $H_{\mathrm{a}}=2 \mathrm{~K}_{1} / M_{\mathrm{s}}, H_{\mathrm{a}}$ is proportional to the magnetic crystal anisotropy constant $\left(K_{1}\right)$, and the inverse proportional relationship with $M_{\mathrm{s}}$ [23]. According to the contribution of different lattice positions to $K_{1}$, the $2 \mathrm{~b}$ position has the greatest effect on $K_{1}$. Therefore, the more components are doped, the greater the effect on $H_{\mathrm{c}}$. For the components $x=0.2,0.6$ and $0.8, H_{\mathrm{c}}$ is declining trend with the increase of the doping. Because the changes of the grain size and $M_{\mathrm{s}}$ are weak, the declining trend of the $H_{\mathrm{c}}$ is contributed to the influence of $K_{1}$. The reason why $H_{\mathrm{c}}$ of BFTO-0.4 ceramic sample sharp declines is relatively complex and can be attributed to two aspects. Firstly, the SEM image of BFTO- $x$ ceramics shows that the grain size of BFTO- 0.4 ceramic sample is larger than that of other components, so the $H_{\mathrm{c}}$ of BFTO- 0.4 ceramics will be smaller. Secondly, the increase of $\mathrm{Ti}^{4+}$ doping and the occupied position would have a greater influence on $K_{1}$, which also causes the obvious change of $H_{\mathrm{c}}$. However, compared to 
BFTO- 0.2 ceramic sample, the saturation magnetization change of BFTO-0.4 ceramic sample is smaller than that of BFTO-0.2. Therefore, the effect of $M_{\mathrm{s}}$ on $H_{\mathrm{c}}$ can be neglected, and the change of $H_{\mathrm{c}}$ depends mainly on the grain size and $K_{1}$.

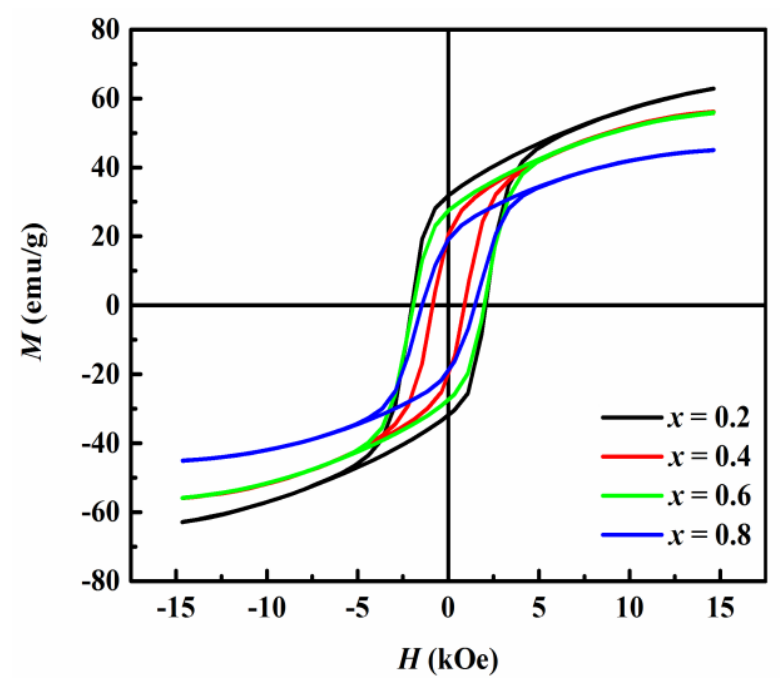

Figure 3. Magnetic hysteresis loops $(M-H)$ of samples at room temperature.

Moreover, refined magnetic structure shows that non-collinear magnetic structure exists in BFTO- $x$ ceramics $[17,24]$. The magnetic moment of primitive cell varies with the doping content of $\mathrm{Ti}$, which is same with experimental data, and the corresponding results was listed in Table 2. The experimental magnetic moment of primitive cell $\left(M_{\mathrm{pc}}\right)$ was calculated by the following formula 1 :

$$
M_{\mathrm{pc}}(\mu \mathrm{B})=\frac{M_{\mathrm{S}}(\mathrm{emu} / \mathrm{g}) \times 1.0783 \times 10^{20}}{N_{\mathrm{A}}} \times \mathrm{M}(\mathrm{BFTO}-x)
$$

where $M_{\mathrm{S}}(\mathrm{emu} / \mathrm{g})$ is the saturation magnetization, $\mathrm{M}(\mathrm{BFTO}-x)$ is the molar mass of BFTO- $x$, and $\mathrm{N}_{\mathrm{A}}$ is the Avogadro constant. From the result of magnetic refinement, the theoretical $M_{\mathrm{pc}}$ fluctuates with the increase of Ti doping, which is consistent with the trend of experimental result.

Table 2. The magnetic moment of BFTO- $x$ ceramics' primitive cell. 


\begin{tabular}{lllll}
\hline & $x=0.2$ & $x=0.4$ & $x=0.6$ & $x=0.8$ \\
\hline Experimental $(\mu \mathrm{B})$ & 12.056 & 11.138 & 10.819 & 11.731 \\
Theoretical $(\mu \mathrm{B})$ & 17.167 & 14.421 & 11.907 & 14.231 \\
\hline
\end{tabular}

\section{3 Effects of titanium substitution on electromagnetic and microwave} absorption properties

The electromagnetic properties of BFTO- $x$ ceramics were shown in Figure 4, which were measured by the air-line method within the $2 \sim 18 \mathrm{GHz}$. According to the figures, the real part of the dielectric permittivity of $x=0.4$ component can reach 25 , while the real part of the dielectric permittivity of other components is smaller to some extent. For the imaginary part of the dielectric permittivity, there are remarkable dielectric relaxation phenomena in all samples, which can contribute to increasing the reflection loss of the absorbing sample. In Figure 4(d), the apparent resonance phenomenon can be observed. It is necessary to note that the natural resonance frequency of the component $x=0.2$ is larger than $18 \mathrm{GHz}$, while the natural resonance frequency of the other three components at a frequency range of $6 \sim 14 \mathrm{GHz}$ illustrated in the inset of Figure $4(d)$ is within the measured frequency range.
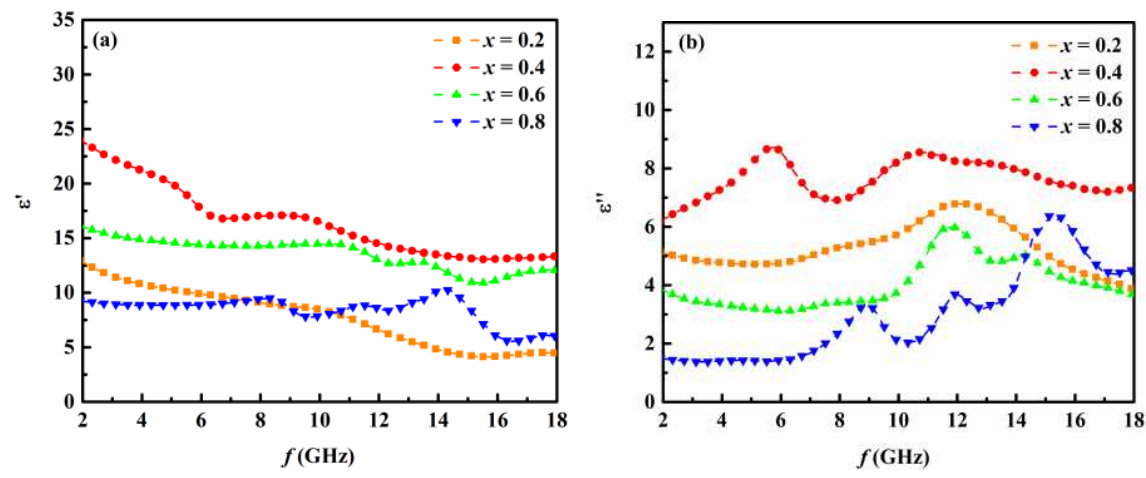

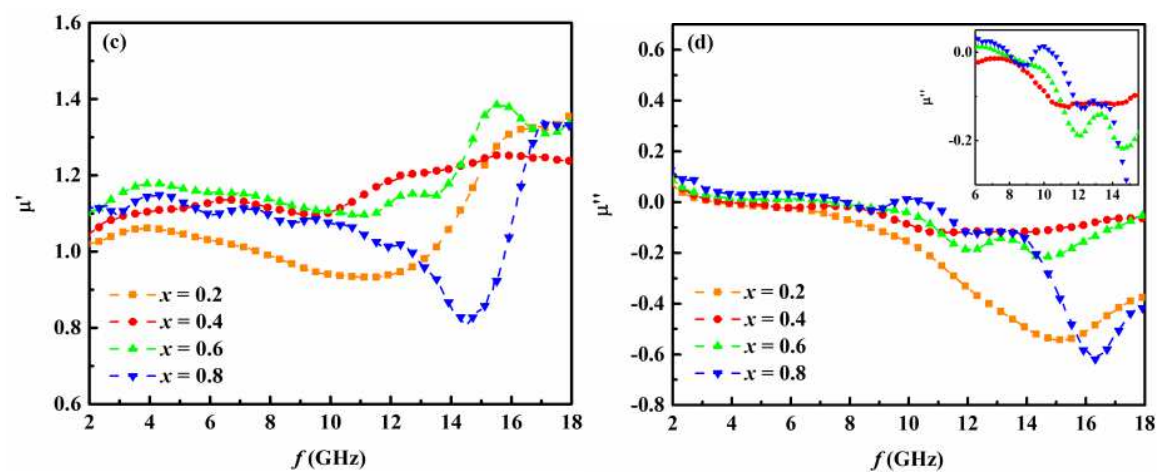

Figure 4. Electromagnetic parameters of PVA mixed BFTO- $x$ ceramics: real parts (a) and imaginary parts (b) of the complex permittivity, and real parts (c) and imaginary parts (d) of the complex permeability.

According to the formula $f_{\mathrm{r}}=1.4 g H_{\mathrm{a}}$, the natural resonant frequency is correlated with the magnetic anisotropy field $\left(H_{\mathrm{a}}\right)$ and the ceramic sample and the Hollande factor (g) [25]. Due to the low anisotropy field of BFTO-0.4 ceramic, the natural resonant frequency of the $x=0.4$ sample is the lowest and appears near $8 \mathrm{GHz}$, while double resonance peaks were obtained in $x=0.6$ and $x=0.8$ components. The high-valence ionic $\mathrm{Ti}^{4+}$ doping, which destroys the valence equilibrium of barium ferrite, will produce a new $g$ factor, and the appearance of double resonance peaks shows that there are two $g$ factors in these samples. With the increase of $\mathrm{Ti}^{4+}$ doping, the anisotropy field decreases, and the natural resonance frequency moves to the lower frequency range. Therefore, the appearance of double resonance peak is advantageous to obtain the larger bandwidth. More evidence can be found in Figure S2, which shows the dielectric and magnetic loss of PVA mixed BFTO- $x$ ceramics. The large dielectric and magnetic loss was obtained in $x=0.2$ sample, which indicates a large reflection loss. The loss curves of $x=0.6$ and 0.8 have evident fluctuation, and, could get large bandwidth.

The reflection loss (RL) of PVA mixed BFTO- $x$ ceramics can be calculated from the measured electromagnetic parameters [26], as shown in Figure 5. The four components of PVA mixed BFTO- $x$ ceramics have obtained a large reflection loss. The 
maximum reflection loss of $-44.9 \mathrm{~dB}$ that means the absorption of electromagnetic waves can reach $99.99 \%$ was obtained in the $x=0.2$ sample, and the thickness is extreme thin, only $1.8 \mathrm{~mm}$. The absorption of electromagnetic waves can also reach $90 \%$ in the other three components. The apparent double absorption peaks appear in Figure 5(c) and (d), which may be origin from the presence of more than one of the Hollande factors in the wave-absorbing material that can benefit for widening the bandwidth of the material. Reflection loss and bandwidth are two important indexes to evaluate the performance of absorbing materials, and high-loss and large-bandwidth materials can be used in a wider range of applications [27].
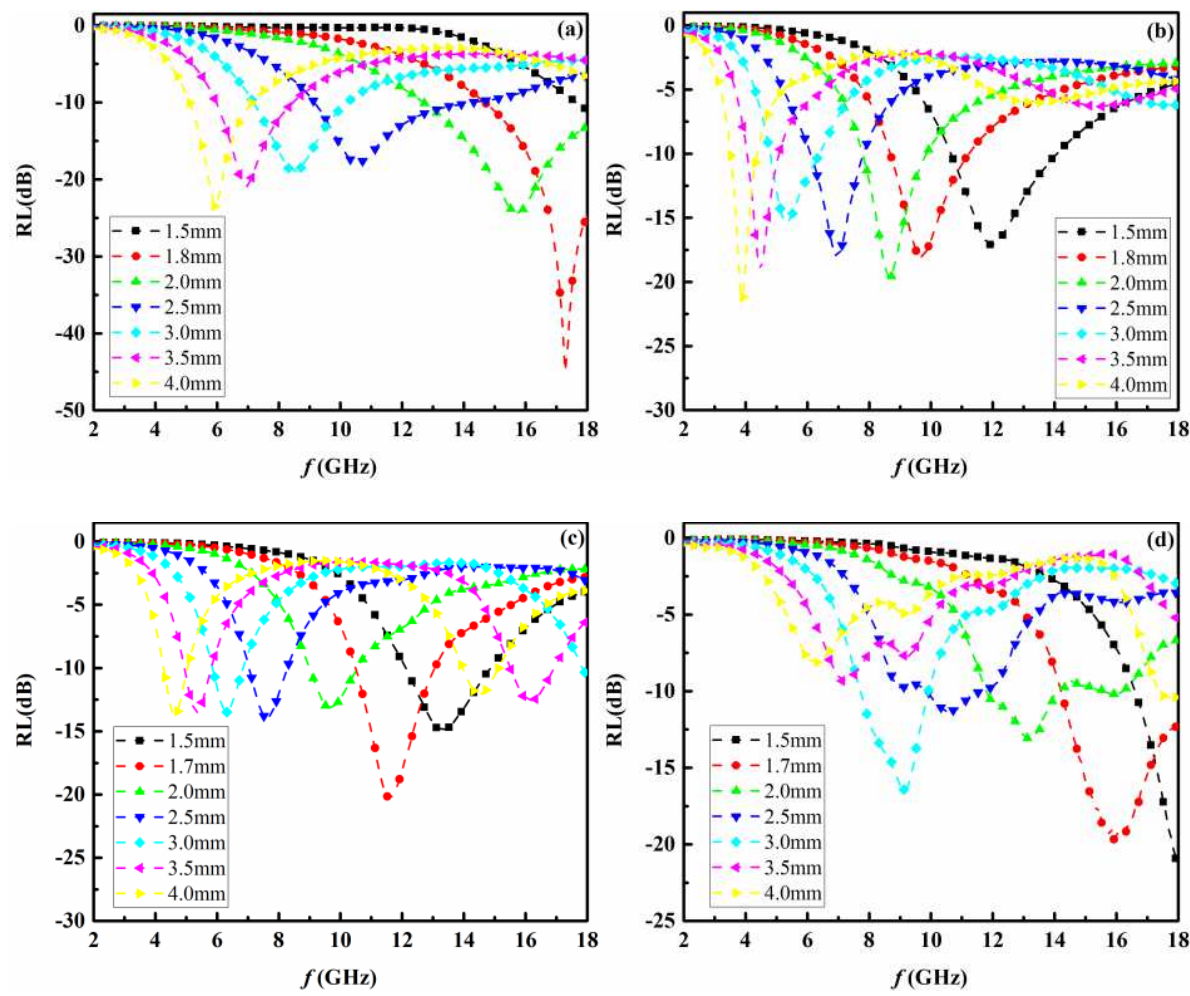

Figure 5. RL curves of PVA mixed BFTO- $x$ ceramics in the frequency range of 2-18 GHz: $x=0.2$ (a), $x=0.4(\mathrm{~b}), x=0.6(\mathrm{c})$, and $x=0.8(\mathrm{~d})$.

Figure 6 shows the 3D RL contour plots of BFTO- $x$ ceramics. As can be seen, all samples perform wide bandwidth in the specific frequency and thickness. Although the 
absorption of electromagnetic waves by this material is not the best, we can find that with the doping of $\mathrm{Ti}^{4+}$ ions, the absorbing properties of M-type barium ferrite have changed significantly. The absorbing characteristics and bandwidth variation in the high frequency band are obvious. This change is mainly due to the transition of trivalent Fe ions to divalent Fe ions, which causes a significant change in the magnetic properties of the material and broadens the absorbing effect at high frequencies [28].
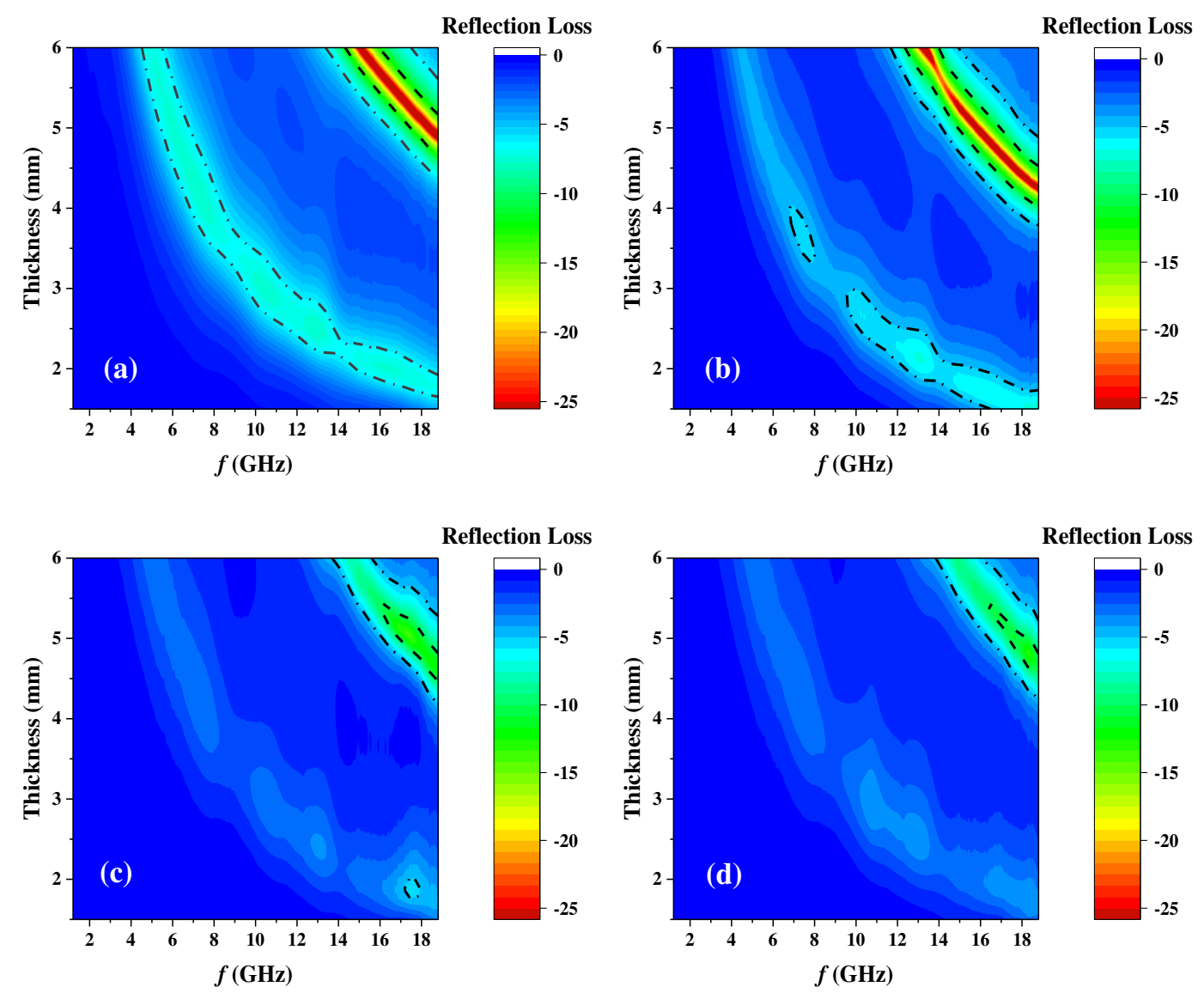

Figure 6. The 3D RL contour plots of BFTO- $x$ ceramics (a) $x=0.2$, (b) $x=0.4$, (c) $x=0.6$, and (d)

$$
x=0.8 .
$$

Figure 7(a) shows the relationship between bandwidth and reflection loss of BFTO$x$ samples, and the maximum reflection loss and bandwidth are listed in Table 3 . For the $x=0.2$, the greatest loss can be obtained at the thickness of $1.8 \mathrm{~mm}$, and the 
bandwidth can reach to $5.28 \mathrm{GHz}$ at $2 \mathrm{~mm}$ when the reflection loss is less than $-10 \mathrm{~dB}$, while the bandwidth of other three components is about $3 \mathrm{GHz}$.
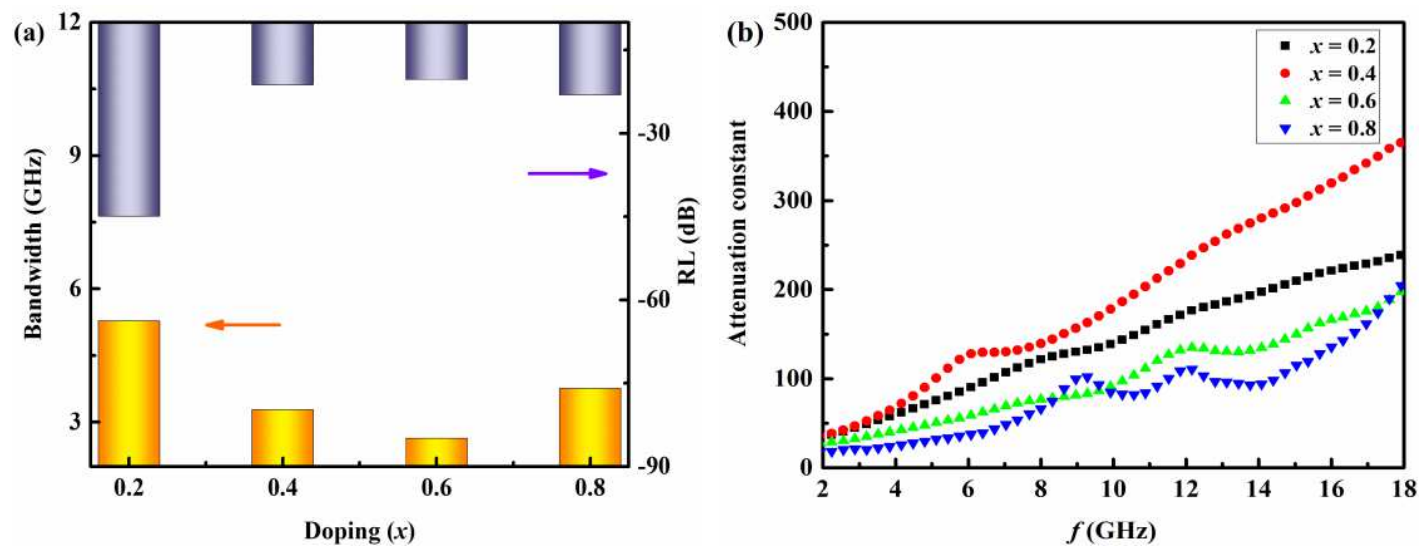

Figure 7. (a) The maximum RL and the corresponding bandwidth over $-10 \mathrm{~dB}$ of each component, and (b) the attenuation constant of BNZFO- $x$ ceramics.

Table 3. The maximum RL and the corresponding bandwidth over -10 dB of PVA-mixed BNZFO$x$ ceramics.

\begin{tabular}{cccc}
\hline Component & Thickness (mm) & Maximum RL (position) & Bandwidth $(<-10 \mathrm{~dB})$ \\
\hline$x=0.2$ & 1.8 & $-44.93 \mathrm{~dB}(17.28 \mathrm{GHz})$ & $3.28 \mathrm{GHz}$ \\
$x=0.4$ & 1.5 & $-17.1 \mathrm{~dB}(11.92 \mathrm{GHz})$ & $3.28 \mathrm{GHz}$ \\
$x=0.6$ & 1.7 & $-20.3 \mathrm{~dB}(11.6 \mathrm{GHz})$ & $2.48 \mathrm{GHz}$ \\
$x=0.8$ & 1.7 & $-19.6 \mathrm{~dB}(15.92 \mathrm{GHz})$ & $3.76 \mathrm{GHz}$ \\
\hline
\end{tabular}

In the ion-doped barium ferrite ceramic, the strong absorbing ability originates from the high attenuation constant [29]. The attenuation constant is expressed by equation 2

$$
\alpha=\left(\frac{\sqrt{2} \pi f}{c}\right) \sqrt{\left(\mu^{\prime \prime} \varepsilon^{\prime \prime}-\mu^{\prime} \varepsilon^{\prime}\right)+\sqrt{\left(\mu^{\prime \prime} \varepsilon^{\prime \prime}-\mu^{\prime} \varepsilon^{\prime}\right)^{2}+\left(\varepsilon^{\prime} \mu^{\prime \prime}+\varepsilon^{\prime \prime} \mu^{\prime}\right)^{2}}}
$$

Herein, $f$ is the microwave frequency and $c$ is the velocity of light. According to the equation, the attenuation constants of the four components of BFTO- $x$ ceramics can 
be calculated, as shown in the Figure $8(\mathrm{~b})$. Within the measuring frequency range of 2 18 GHz, four components have a large attenuation constant, wherein the attenuation constant of $x=0.4$ component is the largest, and is 350 . The variation trend of attenuation constants is similar to that of the imaginary part of magnetic permeability, there is a double resonance peak in $x=0.6$ and 0.8 components. Therefore, the dielectric constant and permeability are the two parameters that determine the microwave absorbing performance, and magnetic and dielectric loss are critical to improve the attenuation of materials to electromagnetic waves.

Besides, frequency modulation is also a standard for measuring the overall performance of absorbing materials. As can be seen from Figure 4-7, the excellent frequency modulation can be obtained in the four components of BFTO- $x$ ceramics. The reflection loss peaks of the $x=0.2$ component are reduced from near $17 \mathrm{GHz}$ to 6 GHz with varying thickness, and the frequency modulation range covers the $69 \%$ of the measuring frequency range, enabling the control of a wide range of absorption frequencies. The frequency regulation ranges of $x=0.4,0.6$ and 0.8 components are 4 12 GHz, 5 18 GHz and 6 18 GHz, respectively. The maximum reflection loss peaks of the four components also moved with the $\mathrm{Ti}^{4+}$ doping content, varying from $18 \mathrm{GHz}$ $(x=0.8)$ to $4 \mathrm{GHz}(x=0.4)$, which covers $81 \%$ of the investigated frequency. In conclusion, all of the four components of BFTO- $x$ ceramics show excellent frequency modulation ability.

\section{Conclusion}

The hexagonal sheet like $\mathrm{BaTi}_{x} \mathrm{Fe}_{12-x} \mathrm{O}_{19}(x=0.2,0.4,0.6,0.8)$ ceramics were 
synthesized by a modified sol-gel method. Through the refined analysis of neutron diffraction, $\mathrm{Ti}^{4+}$ tends to occupy the position $2 \mathrm{a}, 2 \mathrm{~b}$, and $12 \mathrm{k}$ of the structure. Saturation magnetization decreases gradually with the increase of $\mathrm{Ti}^{4+}$ doping, but the change of the coercive force is complex under the synergy of the changed grain size and the magnetic crystal anisotropy field. The excellent microwave absorption performance $44.9 \mathrm{~dB}$ with board bandwidth in the $x=0.2$ component can be attributed to the double resonance peak induced by high valent doping of $\mathrm{Ti}^{4+}$. Meanwhile, the reflection loss peak position of the $x=0.6$ component can be adjusted from $18 \mathrm{GHz}$ to $5 \mathrm{GHz}$ and the remaining components cover a frequency adjusted range of up to $50 \%$, which have a significant potential application value in microwave absorption field.

\section{Acknowledgement}

This work was supported by the National Natural Science Foundation of China (51502054), the Postdoctoral Science Foundation of China (2014M551236), the Postdoctoral Science Foundation of Heilongjiang Province (LBH-Z14083).

\section{Reference}

[1] P. Toneguzzo, G. Viau, O. Acher, et al. Monodisperse ferromagnetic particles for microwave applications. Adv. Mater 1998, 10: 1032-1035.

[2] R. Che, L. Peng, X. Duan, et al. Microwave absorption enhancement and complex permittivity and permeability of Fe encapsulated within carbon nanotubes. $A d v$. Mater 2004, 16: 401-405.

[3] Y. Ding, L. Zhang, Q. Liao, et al. Electromagnetic wave absorption in reduced graphene oxide functionalized with $\mathrm{Fe}_{3} \mathrm{O}_{4} / \mathrm{Fe}$ nanorings. Nano. Res 2016, 9: 2018- 
2025 .

[4] Y. Li, Y. Zhao, X. Lu, et al. Self-healing superhydrophobic polyvinylidene fluoride/ $\mathrm{Fe}_{3} \mathrm{O}_{4} @$ polypyrrole fiber with core-sheath structures for superior microwave absorption. Nano. Res 2016, 9: 2034-2045.

[5] Ye, X., Chen, Z., Ai, S. et al. Porous SiC/melamine-derived carbon foam frameworks with excellent electromagnetic wave absorbing capacity. J. Adv Ceram 2019, 8: 479-488.

[6] S. Chiu, H. Yu, Y. Li, et al. High electromagnetic wave absorption performance of silicon carbide nanowires in the gigahertz range. J. Phys. Chem. C 2010, 114: 19471952.

[7] P. Saini, M. Arora, G. Gupta, et al. High permittivity polyaniline-barium titanate nanocomposites with excellent electromagnetic interference shielding response. Nanoscale 2013, 5: 4330-4336.

[8] J. Jia, C. Liu, N. Ma, et al. Exchange coupling controlled ferrite with dual magnetic resonance and broad frequency bandwidth in microwave absorption. Sci. Technol. Adv. Mat 2013, 14: 045002.

[9] R. C. Pullar. Hexagonal ferrites: A review of the synthesis, properties and applications of hexaferrite ceramics. Prog. Mater. Sci 2012, 57: 1191-1334.

[10] S. V. Trukhanov, A. V. Trukhanov, V. G. Kostishyn, et al. Magnetic, dielectric and microwave properties of the $\mathrm{BaFe}_{12-x} \mathrm{Ga}_{x} \mathrm{O}_{19}(x \leq 1.2)$ solid solutions at room temperature. J. Magn. Magn. Mater 2017, 442: 300-310.

[11] Xu, J., Lu, Q., Lin, J. et al. Enhanced ferro-/piezoelectric properties of tape-casting- 
derived $\mathrm{Er}^{3+}$-doped $\mathrm{Ba}_{0.85} \mathrm{Ca}_{0.15} \mathrm{Ti}_{0.9} \mathrm{Zr}_{0.1} \mathrm{O}_{3}$ optoelectronic thick films. J. $A d v$ Ceram 2020, 6: 693-702

[12] Kumar, Y., Yadav, K.L., Shah, J. et al. Investigation of magnetoelectric effect in lead free $\mathrm{K}_{0.5} \mathrm{Na}_{0.5} \mathrm{NbO}_{3}-\mathrm{BaFe}_{12} \mathrm{O}_{19}$ novel composite system. J. Adv Ceram 2019, 8: $333-344$.

[13] J. Li, S. He, K.Z. Shi, et al. Coexistence of broad-bandwidth and strong microwave absorption in $\mathrm{Co}^{2+}-\mathrm{Zr}^{4+}$ co-doped barium ferrite ceramics. Ceram. Int 2018, 44: 6953-6958.

[14] T. Tsutaoka, N. Koga. Magnetic phase transitions in substituted barium ferrites $\mathrm{BaFe}_{12-x}\left(\mathrm{Ti}_{0.5} \mathrm{Co}_{0.5}\right)_{x} \mathrm{O}_{19}(x=0-5)$. J. Magn. Magn. Mater 2013, 325: 36-41.

[15] C. Liu, Y. Zhang, Y. Tang, et al. The tunable magnetic and microwave absorption properties of the $\mathrm{Nb}^{5+}-\mathrm{Ni}^{2+}$ co-doped M-type barium ferrite. J. Mater. Chem. C 2017, 5: 3461-3472.

[16] C. Liu, Y. Chen, Y. Yue, et al. Formation of $\mathrm{BaFe}_{12-x} \mathrm{Nb}_{x} \mathrm{O}_{19}$ and its high electromagnetic wave absorption properties in millimeter wave frequency range. $J$. Am. Ceram. Soc 2017, 100: 3999-4010.

[17] J. Rodríguez-Carvajal. Recent advances in magnetic structure determination by neutron powder diffraction. Physica B 1993, 192: 55-69.

[18] A. S. Wills. A new protocol for the determination of magnetic structures using simulated annealing and representational analysis (SARAh). Physica B 2000, 276: $680-681$.

[19] Y. Shao, F. Huang, X. Xu, et al. Multi-susceptible single-phase $\mathrm{BaAl}_{x} \mathrm{Fe}_{12-x} \mathrm{O}_{19}$ 
ceramics with both improved magnetic and ferroelectric properties. Appl. Phys. Lett 2019, 114: 242902.

[20] K. Watanabe, J. Kawabe. Growth and characterization of minute $\mathrm{BaFe}_{12-}$ ${ }_{2 x} \mathrm{Ti}_{x} \mathrm{Co}_{x} \mathrm{O}_{19}$ crystals from high-temperature solution. J. Mater. Chem 1997, 7:17971800.

[21] D. A. Vinnik, D. A. Zherebtsov, L. S. Mashkovtseva, et al. Ti-substituted $\mathrm{BaFe}_{12} \mathrm{O}_{19}$ single crystal growth and characterization. Cryst. Growth Des 2014, 14: 5834-5839.

[22] Y. Cheng, X. Ren. Permeability and electromagnetic wave absorption properties of sintered barium hexaferrites with substitution of $\mathrm{Co}^{2+}-\mathrm{Zr}^{4+}$. J. Mater. Sci. Mater. El 2016, 27: 772-775.

[23] C. Singh, N. S. Bindra, I. S. Hudiara, et al. The effect of Co and Zr substitution on dc magnetic properties of Ba-Sr ferrite. J. Alloys. Compd 2008, 464: 429-433.

[24] H. Zhang, C. Rong, X. Du, et al. Investigation on the coercivity and remanence of single-phase nanocrystalline permanent magnets by micromagnetic finite-element method. J. Magn. Magn. Mater 2004, 278: 127-137.

[25] S. P. Gairola, V. Verma, A. Singh, et al. Modified composition of barium ferrite to act as a microwave absorber in X-band frequencies. Solid. State. Commun 2010, 150: $147-151$

[26] J. R. Liu, M. Itoh, K. Machida. Electromagnetic wave absorption properties of $\alpha$ $\mathrm{Fe} / \mathrm{Fe}_{3} \mathrm{~B} / \mathrm{Y}_{2} \mathrm{O}_{3}$ nanocomposites in gigahertz range. Appl. Phys. Lett 2003, 83: $4017-$ 4019.

[27] C. M. Watts, X. Liu, W. J. Padilla. Metamaterial electromagnetic wave absorbers. 
Adv. Mater. 2012, 24: OP181-OP181.

[28] C. Liu, Q. Xu, Y. Tang, et al. $\mathrm{Zr}^{4+}$ doping-controlled permittivity and permeability of $\mathrm{BaFe}_{12-x} \mathrm{Zr}_{x} \mathrm{O}_{19}$ and the extraordinary EM absorption power in the millimeter wavelength frequency range. J. Mater. Chem. C 2016, 4: 9532-9543.

[29] J. Huo, L. Wang, H. Yu. Polymeric nanocomposites for electromagnetic wave absorption. J. Mater. Sci 2009, 44: 3917-3927. 
Figures

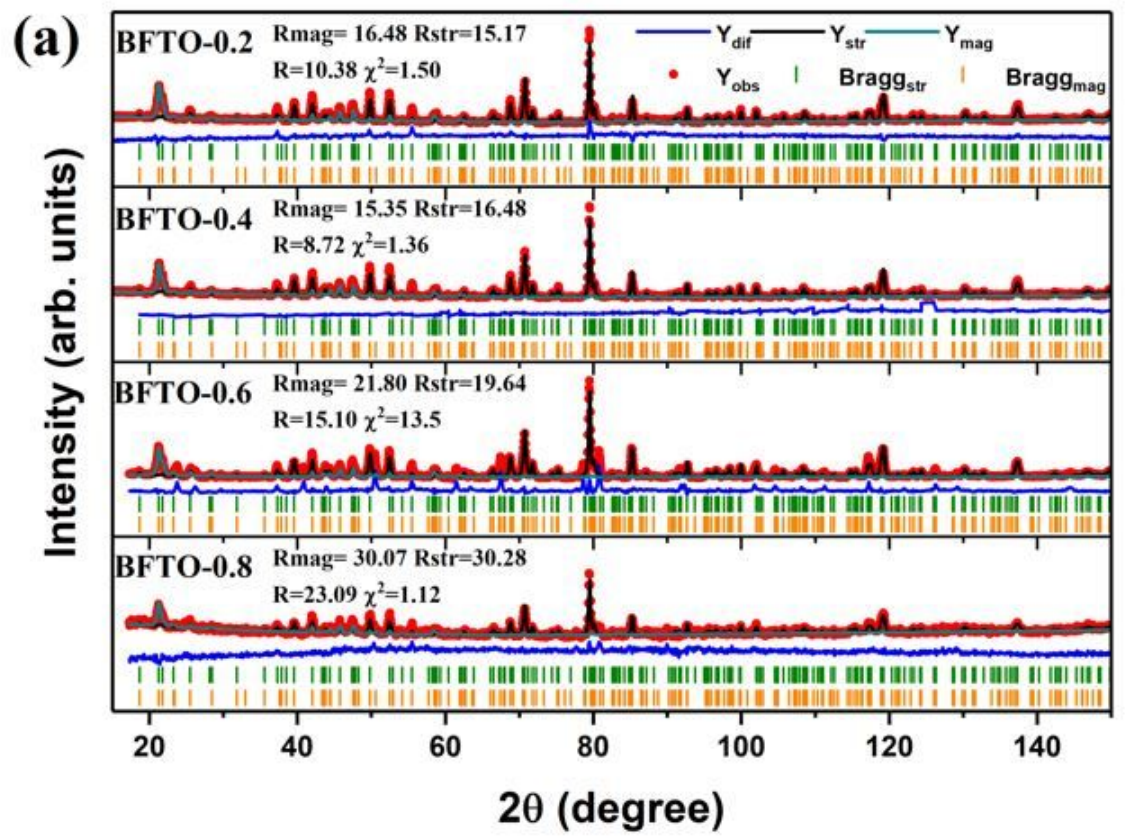

(b)

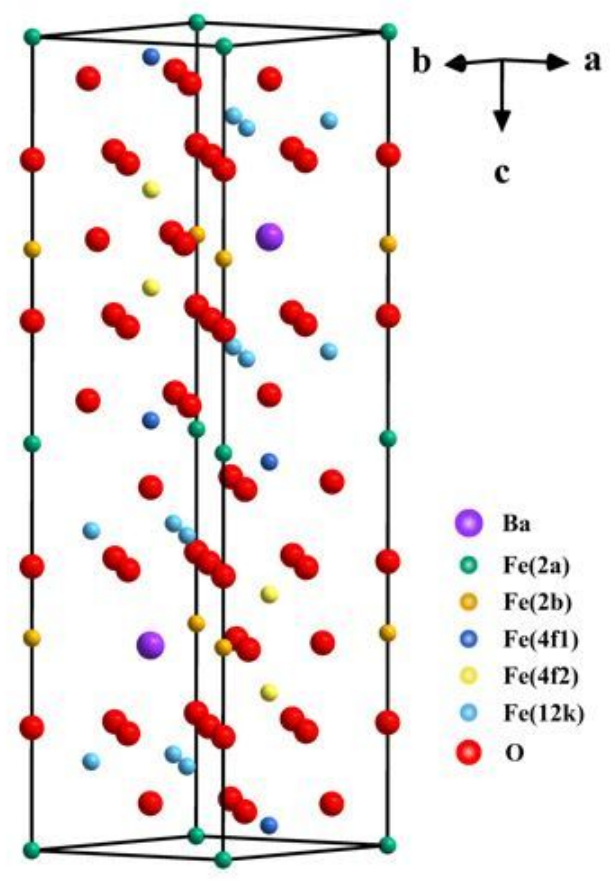

Figure 1

(a) Neutron diffraction and corresponding refinement patterns of BFTO-x $(x=0.2,0.4,0.6,0.8)$ ceramics, and (b) the schematic structure of BaFe12019. 

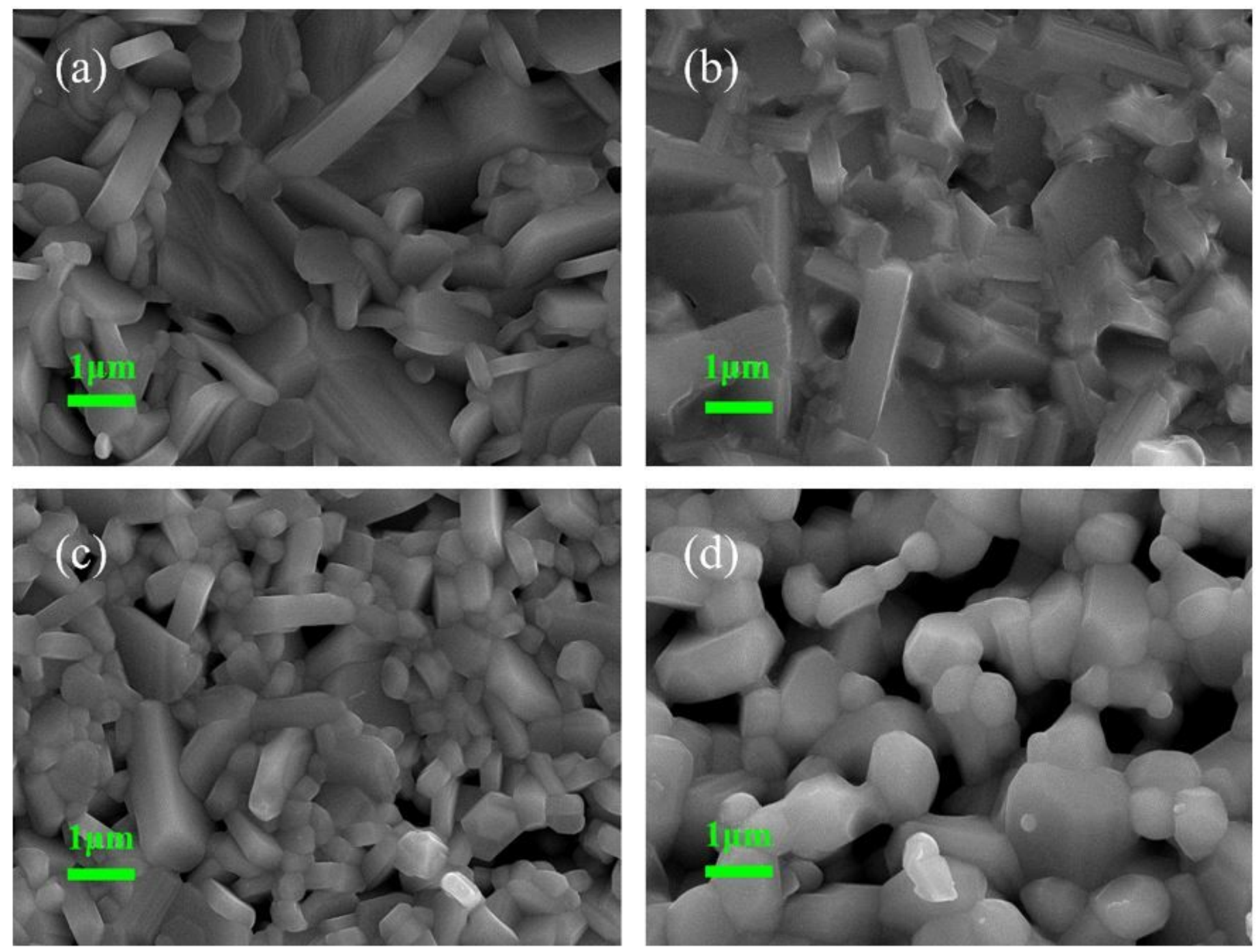

Figure 2

SEM images of BFTO-x ceramics with $x=0.2(a), x=0.4(b), x=0.6(c), x=0.8(d)$. 


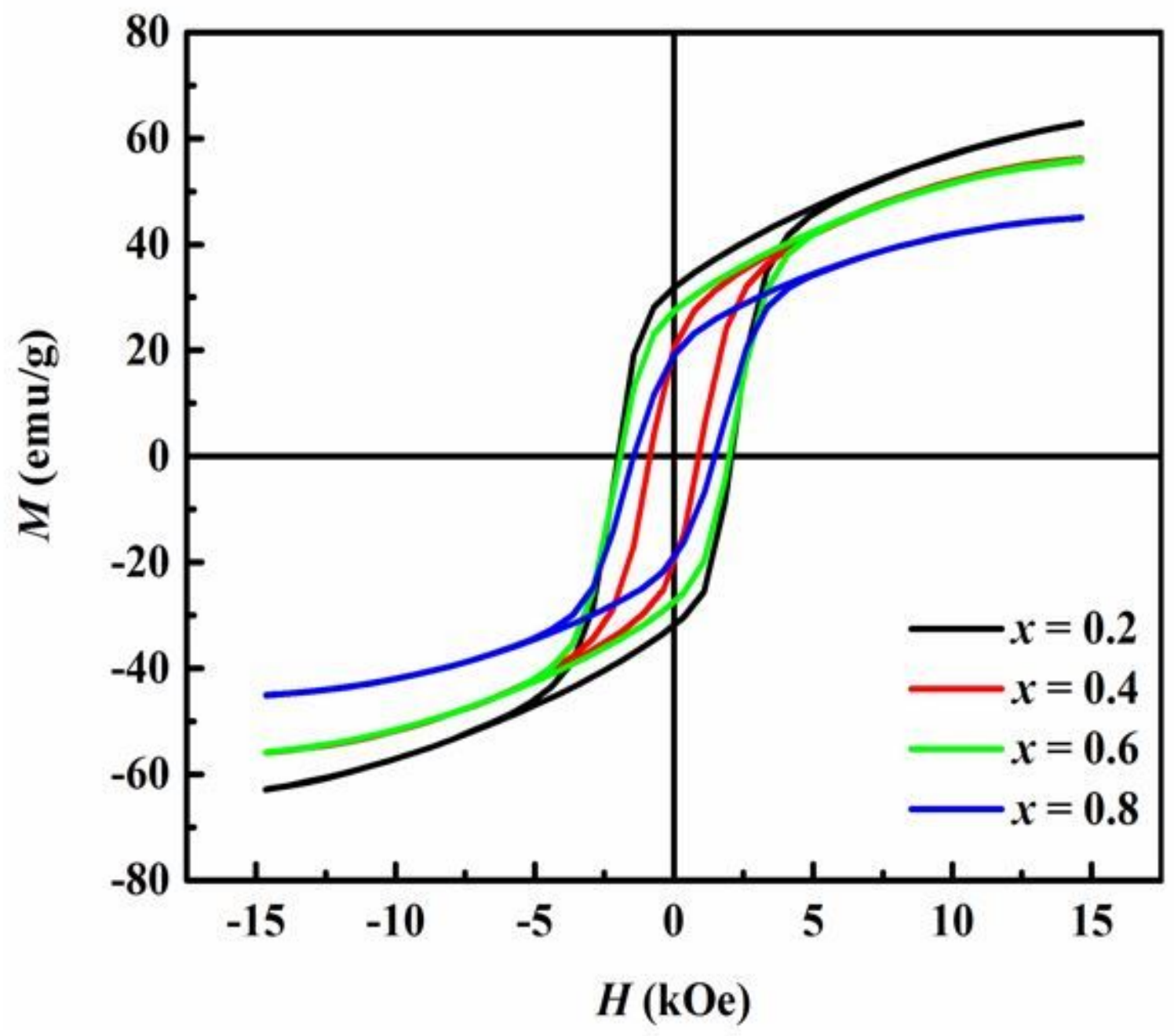

Figure 3

Magnetic hysteresis loops $(\mathrm{M}-\mathrm{H})$ of samples at room temperature. 

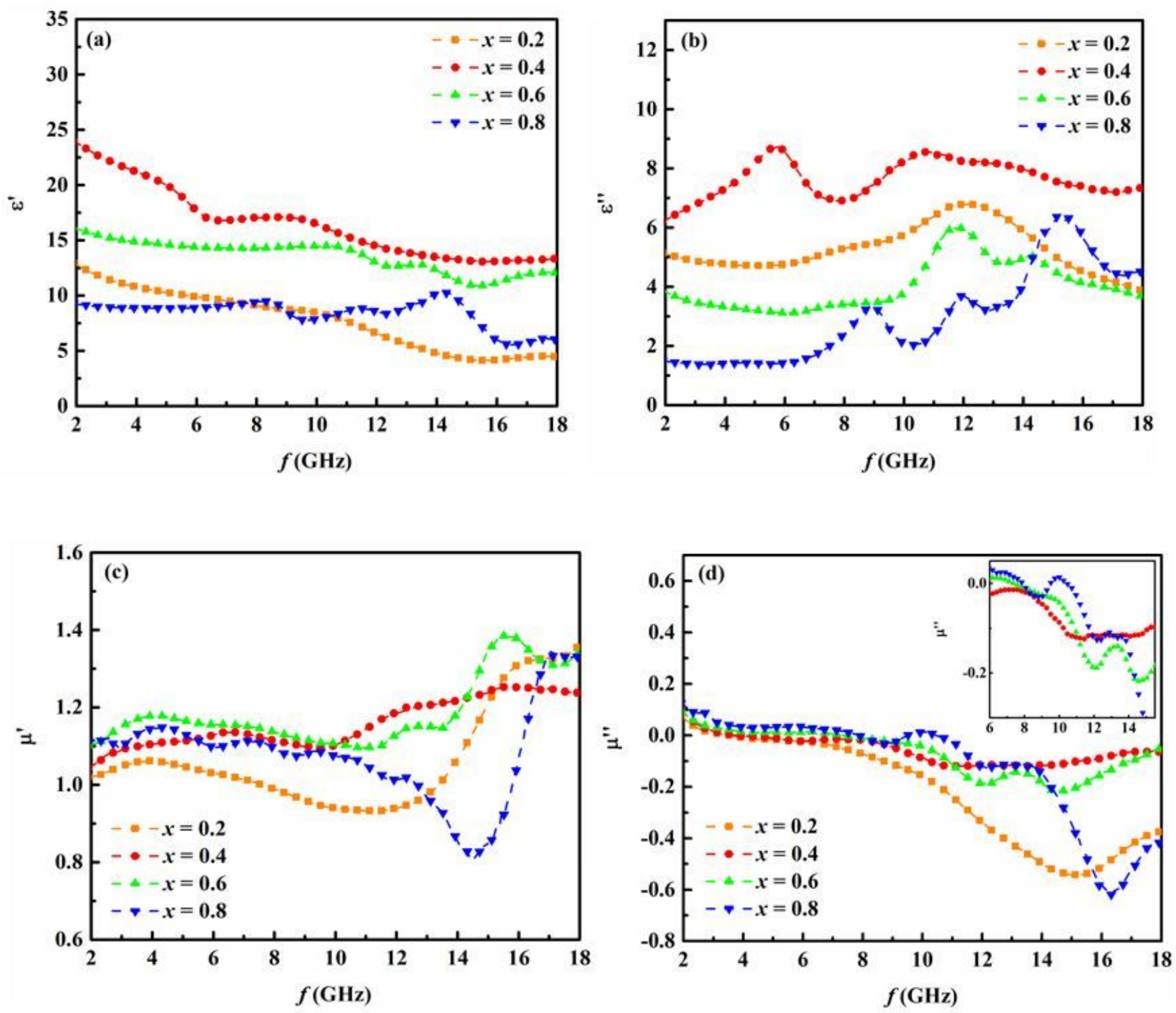

Figure 4

Electromagnetic parameters of PVA mixed BFTO-x ceramics: real parts (a) and imaginary parts (b) of the complex permittivity, and real parts (c) and imaginary parts (d) of the complex permeability. 

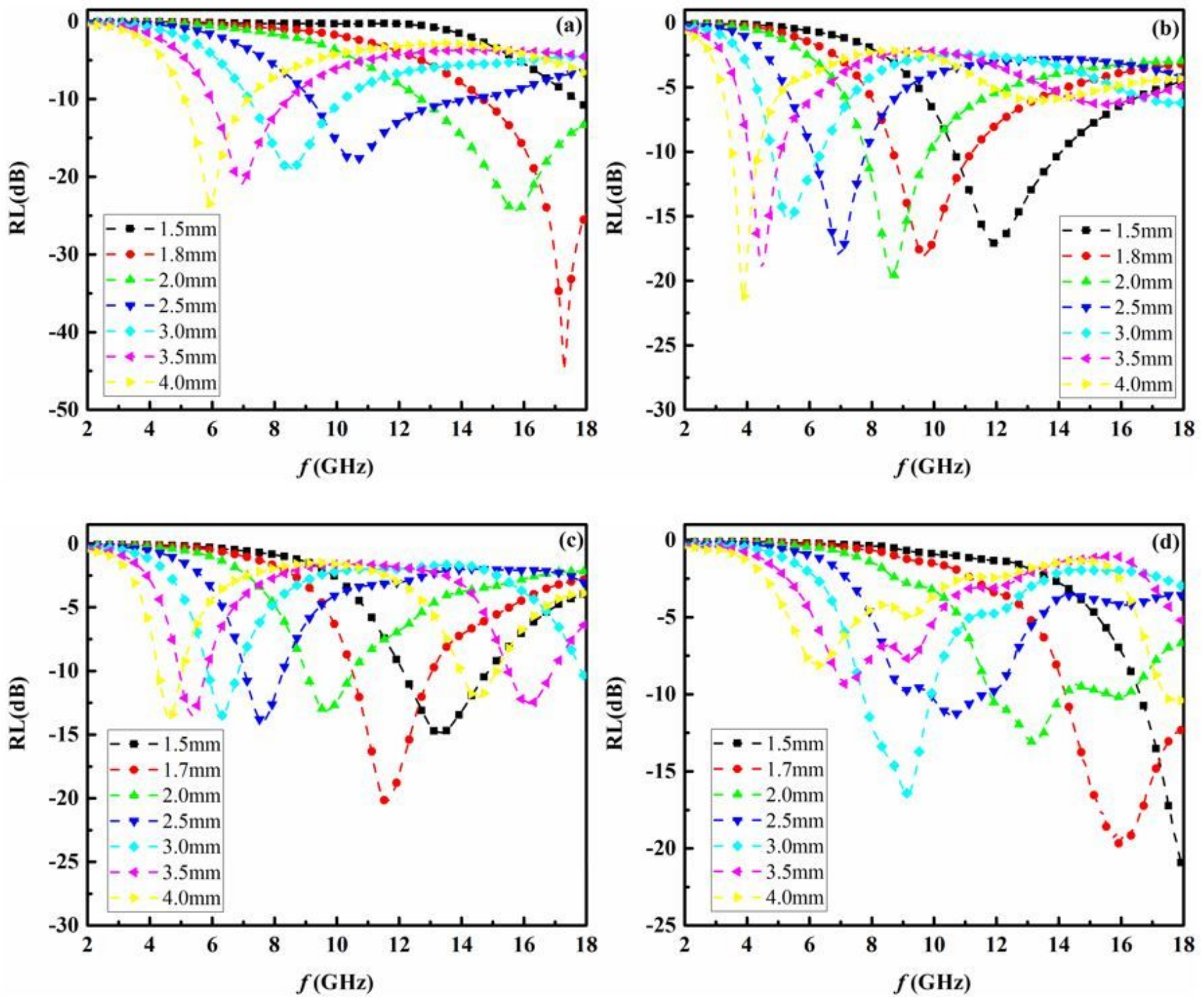

Figure 5

RL curves of PVA mixed BFTO-x ceramics in the frequency range of $2-18 \mathrm{GHz}: \mathrm{x}=0.2(\mathrm{a}), \mathrm{x}=0.4(\mathrm{~b}), \mathrm{x}=$ $0.6(c)$, and $x=0.8(d)$. 
Reflection Loss
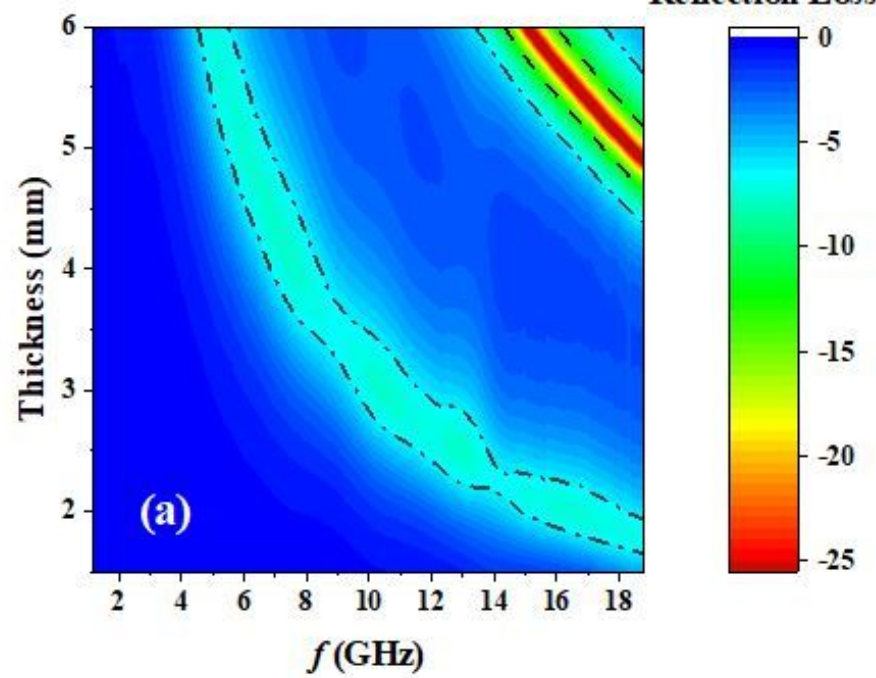

Reflection Loss
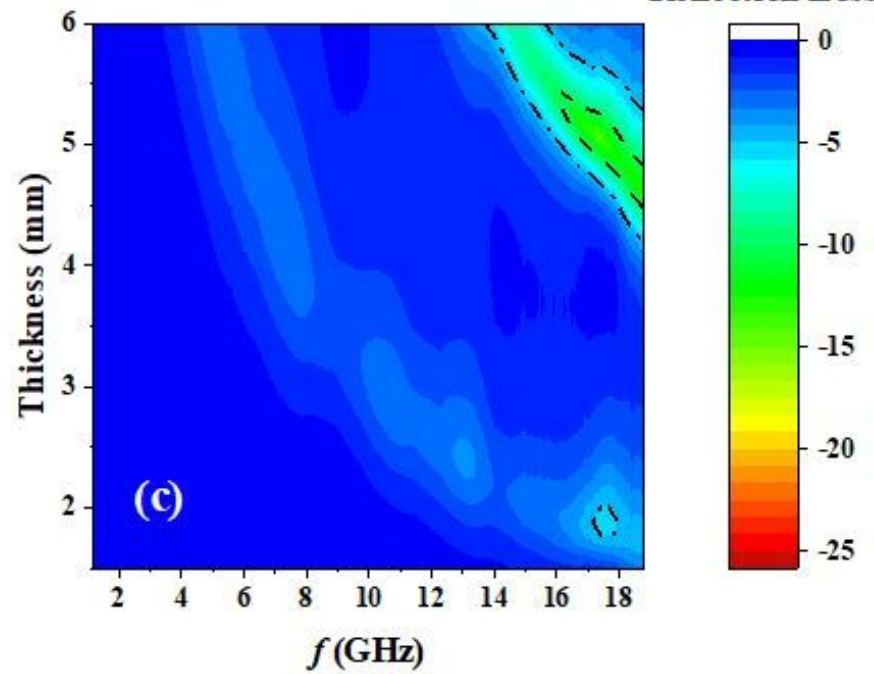

Reflection Loss
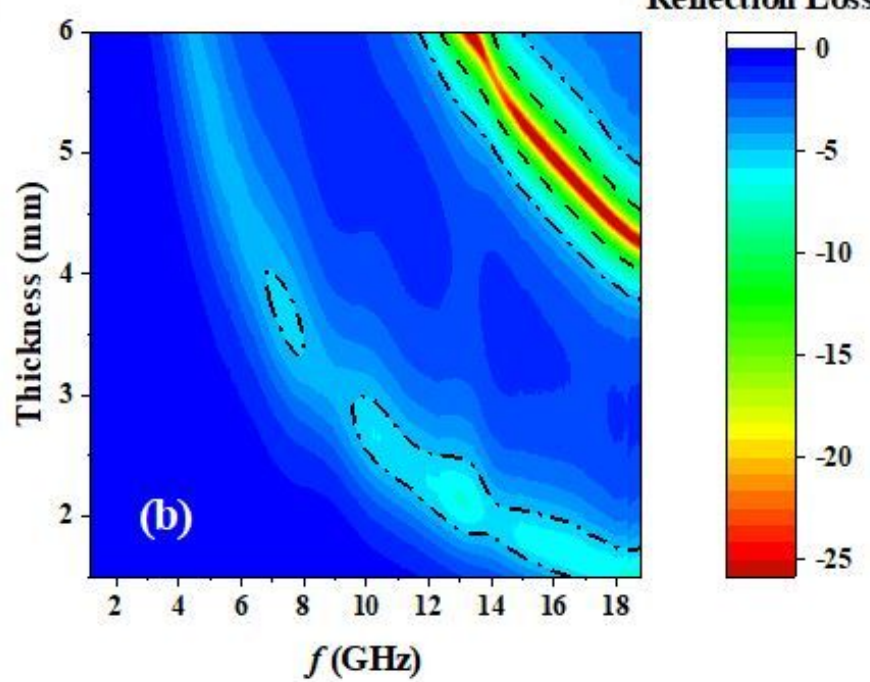

Reflection Loss

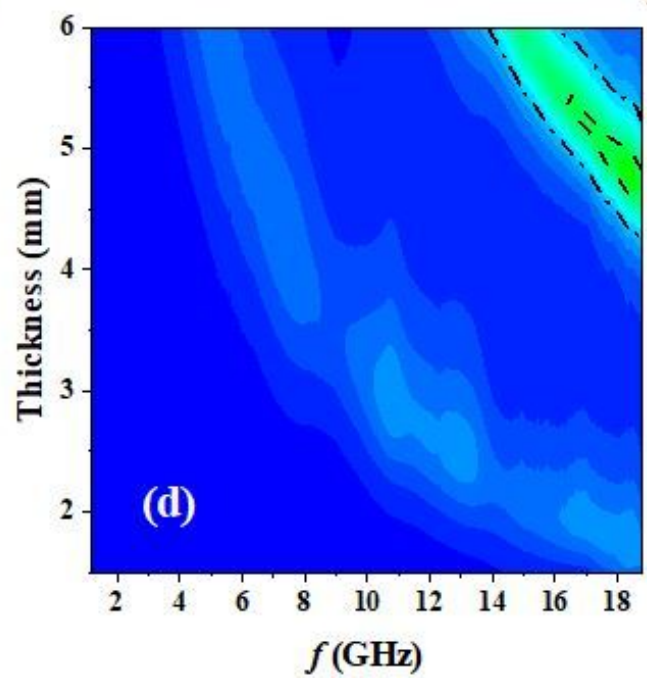

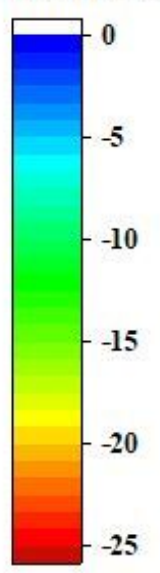

$-25$

\section{Figure 6}

The 3D RL contour plots of BFTO-x ceramics (a) $x=0.2$, (b) $x=0.4$, (c) $x=0.6$, and (d) $x=0.8$. 

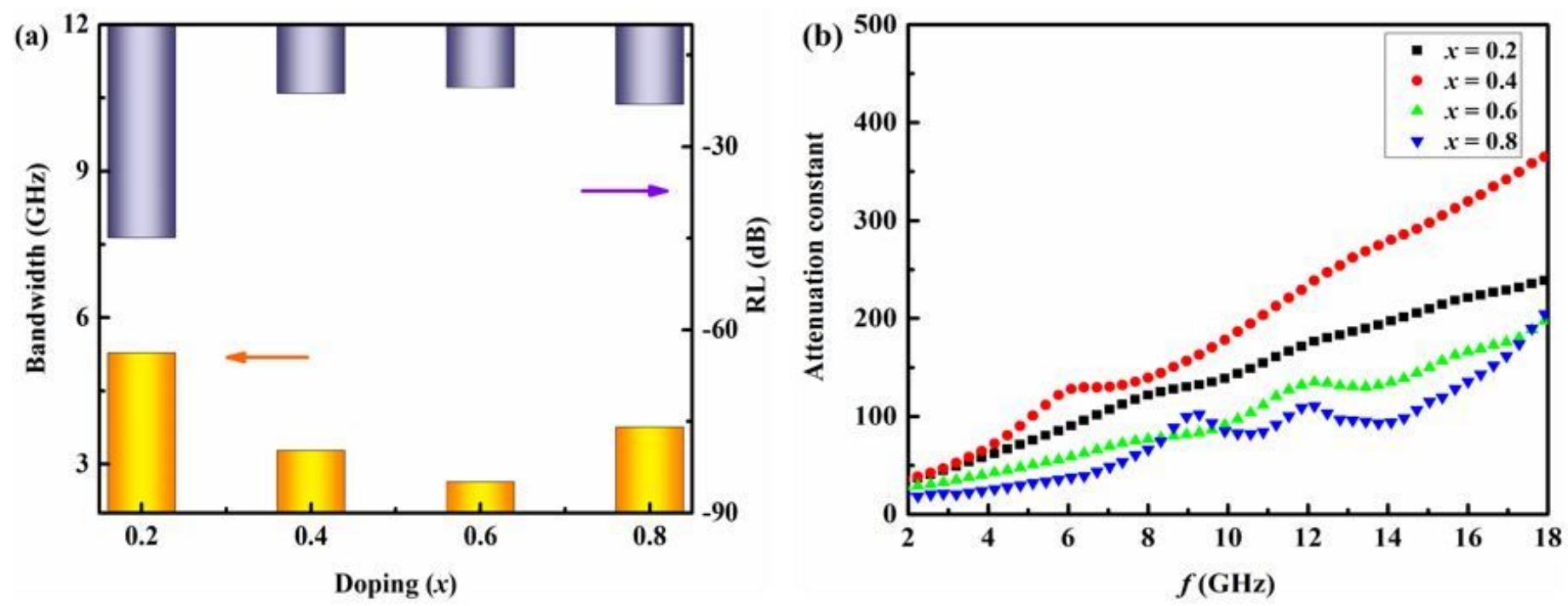

Figure 7

(a) The maximum RL and the corresponding bandwidth over $-10 \mathrm{~dB}$ of each component, and (b) the attenuation constant of BNZFO-x ceramics.

\section{Supplementary Files}

This is a list of supplementary files associated with this preprint. Click to download.

- SupportingInformationJ.AdvC.docx 